\title{
La reconstrucción de una ciudad: la restauración del Templo de Diana de Évora
}

\section{The rebuilding of a city: the restoration of the Temple of Diana in Évora}

\author{
María CÁTEDRA \\ Departamento de Antropología Social. Universidad Complutense de Madrid \\ mcatedra@cps.ucm.es
}

Recibido: 3 de mayo de 2011

Aceptado: 30 de mayo de 2011

\begin{abstract}
Resumen
Este artículo refleja un momento clave de la elaboración simbólica de la ciudad-museo de Évora, en la actualidad Patrimonio de la Humanidad. A partir de la restauración del Templo de Diana en el siglo XIX, los eborenses se apercibieron visual y cognitivamente del origen romano de la ciudad y el monumento, que la corona en su zona más elevada, reestructuró el conjunto de la ciudad y sirvió para reconstruir la imagen posterior. Es una imagen que identificará la ciudad, se convertirá en su exlibris y marcará su historia. Tras un turbulento proceso, los afanes de sus cultos defensores motivaron otras iniciativas posteriores, creando un pionero ambiente de protección y defensa de la ciudad que la caracteriza.
\end{abstract}

Palabras clave: Antropología urbana, restauración, patrimonio, imagen, Évora.

\begin{abstract}
This article reflect a key issue about the symbolic elaboration of a museum-city of Évora, actually a World Heritage City. After the restoration of the Temple of Diana in the XIX century, the people from Evora perceived visually and cognitivelly the Roman origin of their city. The monument, in the top of the city hill, reestructured the whole city and made up its latter image. An image which did identify the city, as its exlibris, and impress its history. After a turbulent process, the cultivated defenders of the temple would propiciate other further iniciatives and build up a pioner and pervasive effort for protection and defense of the city.
\end{abstract}

Keywords: Urban Anthropology, restoration, patrimony, image, Évora.

Referencia normalizada: Cátedra, M. (2011). La reconstrucción de una ciudad: la restauración del Templo de Diana de Évora. Revista de Antropología Social, 20, 309-328.

SUMARIO: 1. Introducción. 2. Mito e historia. 3. Se desnuda el templo. 4. Conclusión: un viejo templo, una nueva ciudad. 5. Referencias bibliográficas. 
O templo romano em Évora ostenta hoje na parte mais elevada da cidade, apesar de mutilado, a donairosa elegância da arte greco-romana, deixando retratar no azul do céu seus lindos capitéis corintios, deliciando artistas, inspirando saudades do passado, a poesia das ruínas em toda a sua majestade, maiormente em noites de luar, quando a lua em céu nublado, de espaço a espaço se nos mostra através de suas colunas denegridas. É esplêndido! É sem dúvida o brasão mais venerado de Évora e de suas antiguidades (Barata, 1878: 202).

\section{Introducción}

La segunda mitad del siglo XIX portugués es una época clave en la configuración de la fisonomía e imagen de la ciudad de Évora y el valor simbólico que se le atribuye, un momento fundamental para entender el significado de la llamada ciudad-museo ${ }^{1}$. Uno de sus hitos principales lo constituye la restauración del templo romano de Évora en 1870, sobre el que me ocuparé en estas líneas.

Según cuenta Barata, quien presencia el hecho, el 17 de Junio de 1870, se arrimaron unas escaleras al edificio que albergaba el templo de Diana de Évora y por ellas subieron el Presidente de la Cámara Municipal, Manuel de Paula da Rocha Viana, y el arquitecto, artista y escenógrafo italiano Giuseppe Cinatti. El presidente de la Cámara le dio al artista un martillo de demolición, con el que éste "jubiloso" inicia el derrumbe simbólico - "sem saudade das artes e de bom gosto"- de una almena gótica del edificio, una especie de viejo torreón "emplasto ridiculo e anacrónico que escondia a beleza, a elegância da mais veneranda relíquia do povo romano não só em Portugal, mas em toda a península" (Barata, 1878: 195). El caserón desde 1836 había dejado de tener la función tradicional de açougue o carnicería y amenazaba ruina en ese momento. La decisión de demolición de los añadidos medievales, que se venía gestando desde hacía años, era defendida por el Director de la Biblioteca Pública, Augusto Filippe Simões, y se toma con una fuerte contestación de sectores de la ciudad y tras consultas a eminentes escritores, artistas, arquitectos y arqueólogos de Portugal.

La demolición, vigilada por Viana, Simões y Barata, bajo la dirección de Cinatti, empieza a ofrecer restos romanos: fustas, inscripciones, restos de capiteles y también monedas de diferentes periodos de la monarquía portuguesa.

\section{Mito e historia}

El llamado templo de Diana se considera hoy día el exlibris de la ciudad cuya silueta aparece repetidamente representada en los más variados contextos. Se ha considerado un objeto imprescindible para abordar el origen y la evolución e historia de la ciudad (Dias, 2007-8).

Desde el siglo XVI todos los escritores de corografía portuguesa han considerado que el templo lo construye Sertorio, una figura legendaria asociada a Évora,

${ }^{1}$ Este ensayo es parte del proyecto de investigación que dirijo en la actualidad del Plan Nacional I+D+I, titulado La reutilización de la cultura en las políticas de intervención social (CSO2008-03427). Agradezco a Jorge Freitas Branco su atenta lectura y comentarios. 
quien se supone construye en la ciudad su casa, las murallas y un acueducto. Si bien el humanista André de Resende no se refiere al templo concretamente (Abreu) más que con la alusión de que el acueducto da Pratta termina en "o pórtico em o mais alto da cidade" (Resende, 1783) ${ }^{2}$, es el primero en señalar el origen romano de la ciudad, familiarizado como está con la Antigüedad Clásica tras un periplo por Roma y otras capitales europeas; también otorga un papel protagonista a Sertorio en esa construcción de las más básicas estructuras de la ciudad. Los escritores posteriores, como Gabriel Estaço en 1625, se refieren al templo indirectamente "Primeiramente esta cidade é antiga... Desta sua antiguidade dá testemunho um hermoso pórtico de colunas corintias que nela há" (1625: 164) ${ }^{3}$.

Su identificación como templo surge en el XVII con un gran fabulador, Fialho, quien crea la leyenda del templo de Diana, diosa de la caza. El contexto de tal adscripción es la lucha de Viriato, el héroe lusitano por excelencia, contra los romanos. Tras su muerte le sustituye el romano disidente Sartorio, quien es, en palabras de Fialho, "outro Viriato ressuscitado" (Fialho, 1942: 122), un capitán que desean los lusitanos para que les libre de la opresión, miseria e infamia de los gobernadores romanos, y al que envían una embajada secreta desde Évora para que les lidere. Sertorio acepta el ofrecimiento el 80 a. C. y con 2600 romanos, 700 africanos y 600 eborenses como guardia toma 20 ciudades o pueblos que se le entregan ${ }^{4}$. Vuelve a Évora y organiza un senado con naturales ilustres de la ciudad y algunos romanos. El nombre de Diana viene provocado por este incidente: "Um Lusitano chamado Hispano lhe trouxe e ofereceu uma serva, ainda pequenina que acaso achara nos matos viva e esperta". Sertorio finge que la cierva guarda un misterio, la amansa y la cuida y les hace creer a los suyos que la cierva viene del cielo, de la diosa Diana que la envía para revelarle el futuro y ayudarle en el gobierno. La cierva incluso aparecerá en las monedas de la época. Se casa con una señora principal y noble de la ciudad, hija de Firmio Labenio, con lo que se convierte en el más ilustre de sus vecinos "estimando mais que tudo a sua Lusitânia e principalmente a sua Évora que já tinha por pátria sua como própria de sua eleição" (Fialho, 1942: 129). Otro autor que resume la obra de Fialho confirma esta vecindad, indicando que Sertorio instituye en Évora un senado, "semelhante ao de Roma e levantou um templo a Diana, a quem venerava por especial protectora e finalmente por cativar de todo os corações

${ }^{2}$ Tampoco se refiere al templo Vasconcelos (1593), obsesionado como Resende por la epigrafía romana, real o imitada, ni Faria que tan sólo dice: "e Sertorio edificou os muros, acueductos e fabricas Corinthias dos despojos daquelle povo" (Farinha, 1785). Costa (1708) no da noticias del templo romano, aunque se refiere a los muros y al acueducto.

${ }^{3}$ Es posible que ese pórtico no fuera el templo. Según Hauschild, la zona del templo estaba cercada por una plaza con pórtico y anuncia nuevas excavaciones para descubrir los cimientos de ese pórtico (1991:114).

${ }^{4}$ Sigo aquí el manuscrito publicado en fascículos por Armando Gusmão a partir de 1942 en $A$ Cidade de Évora, Año $1^{\circ}, \mathrm{n}^{\circ} 1$. Fialho trabajó en el manuscrito unos veinte años hasta su muerte en 1718 y su extensa obra de 4 volúmenes no fue publicada. Su trabajo se conoció por el resumen y añadidos de sus coetáneos Fonseca (1728) y Franco (1945). En la copia que escribe y amplifica Fonseca hay algunos cambios significativos; por ejemplo, acompañan a Sertorio 4.000 portugueses a pié y 700 a caballo de los que 600 son eborenses y forman su guardia. 
dos Eborenses fundou Palácio em Évora para a sua Pessoa e se casou..." (Fonseca, 1728: 21). A la muerte de Sertorio se le entierra, según algunos, en un mausoleo que "estava junto do templo da sua querida Deusa Diana" (Fonseca, 1728: 27).

Amador Patricio - seudónimo de Martim Cardoso de Azevedo- algo más tarde le da aún una mayor antigüedad al templo. Los griegos llegan a Évora a un campo muy fértil y fresco, donde aparece a la luz de la luna una mujer o ninfa muy hermosa, y pensando que podía ser una diosa todos se postraron reverenciándola. Era Diana, natural de Évora, muy aficionada a la caza. Los extranjeros ante el peligro de naufragio habían hecho votos y promesas de hacer un templo afamado y adorar a la primera cosa que en tierra les diese alivio; como Diana les mandó presentes y refrescos, se decidieron a dedicarle el templo. Los eborenses les ayudaron en esta tarea y en poco tiempo terminaron una obra muy suntuosa, el famoso Templo de Diana "onde agora estão os açougues da carne junto á Inquisição" (1739: 33).

No hay ninguna prueba de la estancia de Sertorio en Évora y se considera que el acueducto es muy posterior, pero la ironía es que los descubrimientos arqueológicos han demostrado el origen romano del palacio y del acueducto además de la llamada cerca velha (Silva, 1997). La ciudad tuvo su importancia como municipio romano tomando el nombre de Liberalitas Iulia en tiempos del emperador Augusto - entre 27 a. C. y 14 d. C.- . El templo ocupa el foro y estuvo dedicado al culto imperial, construido hacia el siglo I o inicios del II d. C. (Dias, 2007-8), aunque distintos autores dan fechas diferentes ${ }^{5}$. Évora tendrá unos quinientos años como ciudad romana. El templo fue en parte destruido en el siglo IV o $\mathrm{V}$ y tuvo diversos usos como edificio religioso, torre militar y, a partir del siglo XIV al menos, como "açougue" - mercado o carnicería ${ }^{6}$ - hasta 1836. Estos diferentes y continuos usos han permitido la conservación del templo a través de los siglos. En época medieval se construyen entre sus gráciles columnas unos toscos tapiales. En el XVI hay una representación del templo pintado en el Foral Manuelino de Évora (Silva, 1997). En varios momentos de su larga historia parte de sus restos se utilizan para construir otros edificios como el castillo de Évora?

${ }^{5}$ Espanca (1997:75) lo considera del siglo III d.C. en la época de Trajano o Adriano y en parte destruido en las persecuciones del paganismo decretadas por Honorio en el 395 d.C. En Wikipedia se afirma que el templo fue construido en honor de Cesar Augusto probablemente en el siglo I a.C., modificado en el II y III y destruido en el siglo V. Hauschild (1991) lo considera de inicios del siglo I, algo posterior a los templos de Barcelona y Mérida.

${ }^{6}$ Como açougue ya lo denomina el cronista Fernão Lopes con ocasión de las revueltas por la sucesión del rey D. Fernando entre el Mestre de Aviz — futuro rey de Portugal— y la reina $\mathrm{D}^{\mathrm{a}}$ Leonor Teles y el pretendiente castellano en enero de 1384.

${ }^{7}$ La reutilización de las piedras parece ser muy común. En 1467 Alfonso V da permiso a un hidalgo de retirar dos piedras del açougue para ennoblecer las ventanas de su casa (Viterbo, 1889-1922: 307, Vol I, en Prata 2010: 7), aunque también hay intentos de restitución. Felipe II manda que se restituyan las piedras "de lugares particulares donde estavão encubiertas e restituidas a praça publica" (Abreu). Victor Bastos, ya en el siglo XIX, señala que hay dispersas por la ciudad varias de las piedras que pertenecen al templo "uma pedra da architrave na parede de uma casa que servia de prisão na praça" (citado en Barata, 1878:198). 


\section{Se desnuda el templo}

En 1836, justo cuando deja de tener su función como açougue, comienza a ofrecer una nueva lectura. Cunha Rivara, director de la Biblioteca Pública y continuador de la obra del arzobispo Frei Manuel de Cenáculo ${ }^{8}$, toma la iniciativa en 1840 y junto a João Raphael de Lemos realiza excavaciones arqueológicas —al demoler el edificio anexo de la Inquisición-, lleva a cabo los primeros trabajos de salvación del templo y recoge en el edificio la colección arqueológica de Cenáculo que dará lugar al futuro Museo de Évora. Pero será el sucesor de Rivara como Director de la Biblioteca Pública, Simões, el que concretiza el proyecto de restauración a partir de 1863. La labor de Rivara al frente de la Biblioteca debió ser considerable. Barata en una nota protesta de haber encontrado olvidados en un desván los 14 volúmenes de lecturas que Rivara hiciera de los documentos más importantes de la Cámara, encuadernados por encargo del Presidente Viana y luego olvidados por la siguiente corporación: "condenados ao acender do fogão da sala das sessões da Câmara!" (Barata 1878: 193, nota 14). También Simões se duele en las últimas páginas de su texto de que los vestigios, fruto de estas excavaciones de Rivara y Lemos, "que deveriam ser tão cuidadosamente conservados como o própio templo, já os não chegámos nós a ver. Tinham sido destruidos antes de 1863 para embelezar o largo e as ruas próximas" (Simões 1888:140).

Tanto Augusto Filipe Simões (1888) como António Francisco Barata (1878) son protagonistas y testigos de la restauración y ellos mismos narran la historia del edificio y su participación en el proceso poco después de producirse 9 . Pero antes me voy a referir a un interesante documento publicado en español, cuando todavía el templo es açougue (Anónimo, 1836), titulado "Ruinas de Portugal". El autor, antes de comentar sobre el templo, ofrece una breve panorámica de la ciudad y su historia ${ }^{10} \mathrm{e}$ indica:

${ }^{8}$ La idea de biblioteca pública y su uso público se remonta al siglo de las Luces, donde se encuadra la creación de la institución por Frei Manuel de Cenáculo, arzobispo de Évora, en 1805, quien la imagina - Estatutos da Biblioteca 1811 - para la utilización no sólo del clero sino los fieles, es decir, se promueve un servicio de lectura pública. Su primer director no religioso, Cunha Rivara, profesor de Liceo, solicita en 1845 fondos para la adquisición de obras modernas de los últimos 50 años y en 1864 Simões, también profesor del Liceo, solicita libros que puedan aprovechar sus alumnos, usuarios de la Biblioteca, y periódicos.

${ }^{9}$ Las fechas de publicación de ambos trabajos no se corresponden con las que son escritas. En su texto Simões indica, doliéndose del poco interés suscitado: "Decorreram dois annos depois da concluida a obra da restauração das ruinas. Em Portugal não foi ainda, que nos conste, julgada por algún escriptor...Evora, a pesar do caminho de ferro, está tão longe de Lisboa..." (Simões, 1888: 139). Y ya se refiere al artículo de Barata que se publica previamente en el Instituto Vasco da Gama, en 1872 (Goa, tomo I, nº 8: 209-210) en relación con un añadido de Rivara a dicho artículo.

${ }^{10}$ Según describe (1836: 169):

Évora está hermosamente situada en una eminencia casi toda cubierta de naranjos, limones, olivos, viñas y huertos de árboles frutales de varias especies, mientras que la vega al pie de la colina está bien cultivada con sembrados de trigo, cebada y otros granos, y a mayor distancia hay bosques espaciosos de alcornoques. Los pueblos que no son puertos de mar, y en los que no hay cantidad de fábricas, no están casi nunca bien poblados; así pues no es extraño que Évora, aunque la cabeza de un arzobispado, no contenga más de 20,000 habitantes. Évora 
El primer objeto que atrae la atención del viajero al entrar en Évora, es el antiguo templo, representado en el grabado de arriba, el que según varias inscripciones parece haber sido dedicado a Diana. Esta fábrica es, sin duda, la más hermosa ruina de arquitectura antigua que ha quedado en Portugal, y una de las muestras más bien preservadas que existen en Europa.

Tras la descripción del templo, el autor se refiere (1836: 170) a su posible origen manifestando su escepticismo sobre la tesis sertoriana ${ }^{11}$ e incluye estos comentarios irónicos sobre su actual función:

Es probable que si Trajano, o Adriano, o cualquiera otro emperador que mandó la erección de esta noble fábrica, hubiesen previsto el destino que le han dado los portugueses modernos se hubieran horrorizado, y si levantado ya, quizás lo hubieran mandado destruir en un arrebato de indignación. No solo es una falta de gusto, mas aun parece una deliberada perversidad, el haber convertido uno de los mas castizos, nobles y delicados templos del siglo de oro, en un matadero. Tal es el templo de Diana en Évora, en el que los carniceros ahora son los sacerdotes, vacas y puercos la congregación, inmundicias el incienso, y las blasfemias consiguientes los himnos a la diosa virgen... Si hemos dejado a nuestros lectores disgustados con la grosera profanación del templo de Diana...

También Barata señala el "baixo e improprio destino" del templo (Barata, 1878: 191) e igualmente Simões, quien indica que en este mismo año de 1836 el

fue tambien distinguida con uno de aquellos memorables e indiscretos tribunales de la Santa Inquisición, distinguiéndose también sus inquisidores en el celo de sacrificar criaturas por la gloria del Criador, y vengar la justicia divina destruyendo inexorablemente a aquellos que la misericordia de Dios permitía vivir para que tuvieran tiempo de arrepentirse en su vida.

${ }^{11}$ Manifiesta que :

El frente de este templo es de aquella especie llamada Hexastila, lo que quiere decir compuesto de seis columnas. Estas columnas tienen vara y cuarta de diámetro, del rico orden Corintio, y han sufrido poco por el estrago del tiempo, y hasta se han librado de la violencia del hombre. El entablamiento está enteramente destruido excepto el arquitrabe. No hay duda en que los Moros respetaron este noble edificio, pues que á pesar de su zelo fanático, lo repararon al estilo oriental, con torrecillas ó mas propiamente almenas, dándole la apariencia de una fortificación; porque apasionados los Árabes á su hermoso estilo de arquitectura, lo mezclaban con el estilo griego y romano, sin chocarles tan manifiesta incoherencia. El resto del edificio está casi en su misma condicion original, y en tan buen estado de preservación que no deja de ser admirable, si se considera que en toda probabilidad hace mas de diez y ocho siglos que fue edificado por los Romanos. Todo el templo está construido con una especie de granito de tanta finura como dureza. Los anticuarios, en sus investigaciones, han suscitado muchas dudas sobre el tiempo de su erección. Algunos lo atribuyen á Quinto Sertorio. Otros, considerando que la arquitectura Romana no estaba tan adelantada en tiempo de este Gobernador, lo atribuyen á tiempos mas modernos; pero á esto responden aquellos, que Sertorio emplearía Griegos en su construcción, lo que no es verosímil en un tiempo en que este caudillo estaba en guerra abierta con Roma. La suposición con mas visos de probabilidad es, que el templo fue construido durante el imperio de Trajano ó de Adriano, los que siendo Españoles de nacimiento, tendrían mas interés en las obras públicas de su país, como el famoso puente de Alcántara, acueducto de Segovia y otras; á lo que se añade que la arquitectura Romana estaba en aquel tiempo en el estado adelantado que representa este templo (1836: 169-170). 
gobernador civil de Evora, José de Avila, hizo "que cessasse aquela ignóbil aplicação de tão venerando monumento" (Simões, 1888: 136), por lo que mandó cerrar las puertas y entregar las llaves a la Cámara municipal a la que pertenecía.

Simões considera que su trabajo sobre el templo es el primer estudio moderno en torno al tema ${ }^{12}$. El artículo comienza con una cita de Platón sobre la educación para apreciar la gracia y la belleza, y se felicita por haber contribuido él mismo a evitar la pérdida del templo "se não residira alguns anos em Évora" (Simões, 1888: 119). Afirma en la introducción que no va a repetir lo que dicen otros con poco fundamento e intenta descubrir " $a$ verdade" (Simões, 1888: 119). Más adelante señala "Até aqui a história; agora a lenda". Alude al origen sertoriano de los edificios romanos de la ciudad - muros, acueducto, palacio y templo-, pero se muestra escéptico por considerar que en una época tan bélica sería muy difícil construcciones tan suntuarias, ya que se necesitan largos periodos de paz y prosperidad para hacer tales obras. Pero además la única prueba de la presencia de Sertorio en la ciudad, una lápida con una inscripción que así lo atestigua, está incluida "na classe das espurias", puesto que fue fabricada por el propio Resende. Así pues, las especulaciones se deben a un "exagerado patriotismo" (Simões, 1888: 123) y afirma que en estas historias se reduce a una época hechos de muchas diferentes. Intenta datar el templo de un modo amplio, teniendo en cuenta otros ejemplos europeos, "como os melhores monumentos peninsulares do estilo greco-romano... con toda probabilidade edificado no século II da era cristã" (Simões, 1888: 130).

En cuanto a la divinidad a la que se consagra el templo, Simões hace un repaso de la historiografía sobre el tema señalando a Fialho como autor de la atribución a Diana. En las excavaciones de 1840, aparecen fragmentos de un altar destruido y un dedo gigante propio de una figura de más de 4 metros, a la que probablemente se dedicó el templo. Pero los aspectos más interesantes de este trabajo tienen que ver con la decisión de restauración del templo y la información sobre el proceso para llevarlo a cabo. En 1863 ya se había desmoronado parte del tejado que cubría el recinto de la torre y las paredes amenazaban ruina con grandes grietas. Allí se guardaban lápidas y otros restos antiguos — algunos de los cuales él mismo había depositado a falta de otro lugar-. Simões se plantea dos soluciones: o reparar las paredes o derruirlas, dejando únicamente lo que era obra romana. Lo primero exigiría mayor gasto y "perpetuaria um barbarismo", por lo que en 1869 Simões propuso a la Cámara municipal la segunda posibilidad en un Relatório de ese mismo año. Sin embargo, hay opiniones adversas entre muchas gentes de Évora:

Uns sequazes inconscientemente das doutrinas utilitárias entendiam que as ruínas do templo não passavam de una antigualha improdutiva, que se havia de deixar cair ou até de pôr terra para desembaraçar o espaço que ocupa. Outros pelo contrário, filiados, também sem o saberem, na escola tradicional, pretendiam que se conservasse religiosamente não só a parte romana mas ainda a da idade média,

${ }^{12}$ Probablemente se refiere al trabajo realizado para el velatorio, dirigido a la corporación municipal en 1869. 
que supunham representante da dominação árabe. Era vulgar a ideia de que o templo, por ter ameias, servira de mesquita aos moiros ... (Simões, 1888: 137) ${ }^{13}$.

O bien por la polémica o bien por que el Presidente de la Cámara estaba finalizando su cargo, no se realiza ninguna actuación hasta que entra como nuevo Presidente por el bienio 1870-1 Manuel de Paula da Rocha Viana, oficial de la Biblioteca Pública, decidido partidario de la demolición de las paredes medievales.

Simões solicita la opinión al respecto a Guiseppe Cinatti, arquitecto y escenógrafo italiano que ha diseñado, dentro del gusto romántico, las llamadas ruinas góticas fingidas del Paseo Público en 1863 y también estaba restaurando el Monasterio de los Jerónimos de Lisboa ${ }^{14}$. El italiano concuerda con la opinión del Velatorio, si bien aporta diversas particularidades técnicas, se ofrece para dirigir la obra y, según Simões, se convierte en un defensor apasionado del proyecto que restituiría la "graça e magestade" del templo, tan familiar para él por su propio origen. Pese a que Cinatti iba con frecuencia a Évora, donde tenía mucha autoridad y era muy popular tras su actuación en el Paseo Público — "Todos viam maravilhados como a fantasia do artista transformara em formosíssimo jardim uns lugares que os muros arruinados, os montes de entulho e as plantas bravias faziam repugnante e desprezivel à vista" (Simões, 1888: 138) - , la opinión pública no era favorable al proyecto. Por ello se hace una consulta a las mentes pensantes del momento ${ }^{15}$, que se decantan por la restauración. Incluso parece que el propio rey dio su opinión - " $a$ conselho do rei artista D. Fernando" (Espanca, 1966, I: 18) ${ }^{16}$-. Uno de los más ilustres y definitivos pareceres es el de Alexandre Herculano, quien va a Évora a ver el templo y se muestra decididamente a favor de la demolición de las paredes, lo que se realiza en 1871, dirigido por Cinatti; tras lo cual todavía algunos, los que suceden a Viana en la Cámara Municipal, se referirán con desdén a "as obras con que tinham desmantelado o templo de Diana" (Simões, 1888:139) ${ }^{17}$. Cuando comienza la obra, Simões cae enfermo y se ausenta de la ciudad, por lo que le sustituye Barata en la supervisión de la obra cuidando con mimo que no se perdieran las lápidas que se encontraban en el templo y las que salieron al tirar las paredes.

${ }^{13}$ En el Velatorio, Simões pensaba conservar dentro del templo la colección arqueológica allí depositada, unos setenta ejemplares, muchos romanos, pero ésta va a parar a la galería del palacio real del Paseo Público que, por cierto, también amenaza ruina, por lo que se pide en el escrito su restauración o alternativamente amenaza con su traslado al Museo do Carmo de Lisboa.

${ }^{14}$ Entre 1808-1879 Cinatti estudió en Milán y desde 1836 vive en Lisboa. Es pintor de interiores, arquitecto y escenógrafo de varios teatros portugueses.

${ }^{15}$ Entre los que responden están el Abbade de Castro, Francisco de Assis Rodrigues, Ignacio de Vilhena Barbosa, José Maria Eugenio de Almeida, Victor Bastos, Visconde de Castilho, y Visconde de Juromenha. Alexandre Herculano da su parecer favorable de palabra y sugiere excavaciones arqueológicas, que deberían realizarse tras la demolición de los añadidos medievales. Barata también cita a Joaquim Possidonio Narcizo da Silva, João Maria Feijóo y José da Silva Mendes Leal y escribe algunos extractos de esos informes (1878: nota 17).

${ }^{16}$ Según Maia (2005-6), Fernando II restauró como mecenas algunos edificios y recogió piezas procedentes de conventos.

${ }^{17}$ Sin embargo, dos años después de terminarse las obras, Simões se refiere, halagado, a los elogios de un extranjero, un español que visita Évora (Simões, 1888:140). 
En su texto Barata se muestra, como Simões, escéptico respecto a la atribución a Diana del templo, pero plantea que puede ser debida a la semejanza con la Maison carrée de Nimes, que se pensó dedicada a Diana ${ }^{18}$. En su texto, más breve y modesto, sin embargo, resume algunos de los dictámenes recibidos tras la circular dirigida a los eminentes sabios. Casi todas las respuestas recogen la idea de la demolición de las paredes y varios recogen la opinión de acoger en el recinto un Museo Arqueológico. Uno de los autores en su respuesta agradece a la Cámara "o desagravo da nossa Diana, tantas vezes, há tantos séculos e tão barbaramente profanada...que chegassem ainda a tempo os vingadores..." (Barata, 1878: 196). Sin embargo, hay una opinión de peso a la que ambos escritores no se enfrentan directamente. Cunha Rivara, el autor de las primeras excavaciones en el templo, "homem a quem Évora muitíssimo deve" (Barata, 1978:193), junto con Lemos, considera un proyecto diferente que supone otra opción de intervención: la conservación de una parte de las paredes construidas en la Edad Media. Es una postura que incide en la noción de patrimonio, como veremos a continuación.

\section{Conclusión: un viejo templo, una nueva ciudad}

La restauración del templo de Diana ofrece distintos significados para la ciudad y para la nación de la que forma parte. En primer lugar, es una de las primeras intervenciones de defensa de la ciudad, llevada a cabo por el empuje y empeño de un grupo de individuos cultos, y el comienzo de una tradición sólida y bien asentada en la actualidad. Diversos autores señalan como esta cultura de defensa de la ciudad se crea en un siglo atribulado, caracterizado por la revolución, el más poderoso agente de la historia portuguesa en el siglo XIX (Bonifacio, 2002:137). Voy a intentar contextualizar este proceso.

A través del templo y su consideración en distintas épocas, se puede apreciar el desarrollo de la propia noción de patrimonio, un concepto históricamente construido y cambiante. Hay diferentes valores asociados al patrimonio en diferentes épocas históricas: valor de conmemoración, de antigüedad, valor patrimonial y valor económico. Entre el Renacimiento y el Romanticismo aparecen estos valores que dan origen a algunas ambigüedades y paradojas que existen actualmente (Prata, 2010).

Aun sin citarlo expresamente, el templo de Diana se reconoce a través de André de Resende, quien señala el origen romano de varias antiguidades evorenses ${ }^{19}$. Ejemplo de escritor renacentista, es miembro de una pequeña minoría elitista que domina los códigos estéticos del momento. La ciudad de Évora en el Renacimiento se vive como un lugar de renovación urbana con la identificación e intervenciones en vestigios patrimoniales, principalmente, romanos, murallas, acueducto, casa... Supone una nueva mirada sobre la antigüedad clásica tanto en su vertiente artística como literaria, en la que se analiza y valoriza el pasado clásico, y se organizan excavaciones para descubrir y recrear ese momento. Los vestigios son monumentos

\footnotetext{
${ }^{18}$ Me parece interesante que se haga mención de la denominación del templo de Nimes y no del de la vecina Mérida, que también tiene un templo similar dedicado a Diana.

${ }^{19}$ Abreu (s. a.), a quien sigo en relación a este autor, considera que quizá ello se debe a las funciones paganas del templo.
} 
históricos: recuerdos del pasado, historia de los grandes hombres u acciones, grandeza de la patria. Pero también es el enaltecimiento de esos restos del pasado como valor de arte absoluto, como ideal clásico. Según Prata (2010), se verifica la distinción entre monumentos - objetos en su contexto - y antigüedades — fuera de contexto - . Los monumentos sirven de modelo de conducta y belleza. Resende es el primero de los defensores de las antigüedades de la ciudad ${ }^{20}$.

A Évora llega la moda de embellecer la construcción pública y privada con materiales arqueológicos y especialmente epigráficos. Así las ciudades también se "leen" a través de las piedras de sus construcciones. Los monumentos que se señalan lo hacen, aparte de la visión positivista como saber de un tiempo pasado, como discurso legitimador de la nobleza de la ciudad. Resende es uno de los más ilustres iniciadores en Portugal de las corografías del XVI, las llamadas "antigüedades y grandezas" que se producen en toda la península. En ellas hay una búsqueda activa de orígenes - respetables - de ciudades y pueblos y de los protagonistas de esos orígenes; Viriato y Sertorio son los héroes fundadores de la nación, prácticamente intercambiables a pesar de su origen tan diverso, unidos por su lucha contra el poder. La pasión de Resende por coleccionar grandezas y por mostrar la antigüedad de su ciudad le lleva a percatarse de los orígenes romanos y a la imitación o fabricación de lápidas que respaldaban sus teorías. Pero lo más interesante es que las referencias de Resende, como ha indicado Abreu, tienen trascendencia en la imagen de la ciudad:

assinalam velhas e novas centralidades urbanas...elementos singulares veneráveis no coletivo social, por concomitância, estruturantes do espaço público...como a Praça do Peixe, rebatizada Praça "de Sertorio"por altura daqueles obras. Com este gesto destronou-se a prosaica função medieval do primeiro nome para o ancorar no passado lendário da cidade tal como a História de Resende o assenta (s. a.: 17).

Un alvará de 20 de agosto de 1721, firmado por João V, marca el inicio de la legislación para proteger el patrimonio y evitar su destrucción. El rey pide al Director y censores de la Academia Real da Historia Portuguesa ${ }^{21}$ que examinen los vestigios de los monumentos de los fenicios, griegos, romanos, godos y árabes para encontrar los restos y antigüedades que por incuria o ignorancia se pueden haber destruido y pide a las Cámaras municipales que las guarden y conserven. El alvará considera que el monumento antigo es el medio para verificar noticias de "venerável antiguidade", al arrojar verdad y conocimiento de los siglos pasados a mayor gloria de la nación y prohíbe expresamente destruir un edificio "que mostre ser daqueles tempos, ainda que em parte esteja arruinado".

${ }^{20}$ Branco (2007:118) señala como Resende rescata de los albañiles una lápida romana con una inscripción que en parte ya estaba quebrada y utilizada como material de obra.

${ }^{21}$ En otro documento, de 4 de febrero de 1802, la responsabilidad de la gestión y tutela pasará al Director de la Biblioteca Pública, lo que explica el papel de Rivara y Simões en la restauración del templo de Diana. 
Este alvará marca el paso de la "antigüedad" al "monumento" que se consolida plenamente en el siglo XIX, la época que paso a analizar con cierta atención ${ }^{22}$. Se puede considerar que las dos fechas claves de actuación en el templo, 1840 y 1870, se corresponden con las dos mitades del siglo. Hay dos hechos de importancia del siglo, que comienza con el saqueo y la destrucción del ejército napoleónico en 1808 y una guerra civil (1832-4) cuyas consecuencias perdurarán durante décadas entre liberales y absolutistas ${ }^{23}$. El resultado es la fuga de la corte a Brasil, la ocupación inglesa y una fuerte emigración de muchos intelectuales a Francia e Inglaterra entre 1823 y 1828 . El exilio permite, sin embargo, cierta conciencia patrimonial tras la victoria liberal. Tanto Almeida Garret como Alexandre Herculano denuncian las alteraciones sufridas en las construcciones medievales y manuelinas, dentro del movimiento romántico.

Sin embargo, aún más importante, en 1834, es la desamortización ${ }^{24}$, el desmantelamiento de las corporaciones y establecimientos religiosos y laicos y la incorporación a la Hacienda Nacional de los bienes "de mão morta" o su venta a particulares. Tras la guerra civil y la consecuente perdida de vidas, hay serios problemas económicos y gastos financieros. La medida intenta resolver la deuda pública e impulsar el desarrollo económico y, al mismo tiempo, consolidar el régimen liberal, ya que la Iglesia tradicionalmente había tomado partido por los absolutistas. Afecta especialmente a las órdenes religiosas masculinas y se nacionalizan sus bienes ${ }^{25}$. Se procede al inventario y clasificación de bienes muebles, bibliotecas, obras de arte, objetos

${ }^{22}$ Sobre el contexto histórico del siglo, he seguido a Bonifacio (2002), Mattoso (1988), Marqués (1998) y Saraiva (1989). Tengo que referirme a datos básicos y obvios para los portugueses sobre la historia de Portugal al escribir para un lector español, poco familiarizado con ella.

${ }^{23}$ Para definir el contexto patrimonial en que tiene lugar el siglo, sigo estrechamente a Maia (2005-2006).

${ }^{24}$ Aunque hay un antecedente en el siglo XVIII con la venta de las propiedades de los jesuitas por el Marqués de Pombal, la desamortización se lleva a cabo en tres etapas: 1821-3, 1832-43 y 186173. La primera se produce por decreto de 5 de mayo de 1821, en que se nacionalizan los bienes de la Corona que pasan a ser bienes nacionales, pero el proceso se interrumpe por diversas alteraciones políticas. La segunda y más fundamental se debe al decreto 30 mayo de 1834, en que se extinguen las ordenes religiosas masculinas y se nacionalizan los bienes. Hacia 1843, ya estaban vendidos todos los bienes. Se extinguen 448 casas religiosas - 356 conventos de frailes y 12 de monjas, en los que en total había 6.289 personas - . La tercera se produce con la desamortización de los bienes de las monjas e iglesias, parroquias, hermandades, cofradías, hospitales, misericordias, beneficencias. Fenómeno de importancia política, financiera, social y económica en toda Europa —Francia, Italia, España-y en contexto de revolución, se ha considerado una condición histórica inevitable para la superación del viejo orden señorial y la implantación capitalista. La venta de bienes se consideró una necesidad, una manera de cambiar el sistema de producción, transformar la estructura social y crear riqueza. Se venden 17.240 propiedades, pero la venta no resuelve de manera significativa el problema financiero. Los beneficiarios son 1.876 compradores, provenientes de la nobleza y clase media, de la burguesía de negocios y del funcionariado público. Un ejemplo en Évora es José Maria Eugenio de Almeida. Sigo aquí a Silva en Mattoso (1988: 293-305) y, para el caso de Évora, a Silveira (1991) y Fonseca (1996).

${ }^{25}$ Se toleraban las femeninas por ser menos peligrosas y al clero secular, más controlado políticamente. A los colaboradores con el miguelismo se les excluyó de los beneficios que se les proporcionó a los no implicados: subsidios, cargos, prestaciones, pensiones..., pero por los retrasos y reducciones y cierta animosidad social, algunos frailes y monjas vivieron en la miseria. En los inicios de los años 60 
de culto de oro y plata, aunque muchos se pierden por el camino. También se nacionalizan enseres domésticos, animales, frutos, rentas, capitales y rendimientos. En cuanto a los bienes inmuebles, se arriendan, y otros se declaran de utilidad para el servicio público como monumentos históricos y de arte.

Según Maia (2005-6), tras la guerra civil, las dos décadas siguientes son claves en el tema del patrimonio. La desamortización ha producido una gran cantidad de bienes nacionales, antes en poder de la Iglesia, muchos en pésimo estado de conservación que hay que restaurar. Se inician museos - Oporto, 1833- y bibliotecas —Lisboa, 1834 - y se acopian obras de arte procedentes de los conventos - Academia de Bellas Artes de Lisboa, 1835- Se decreta la creación en todas las capitales de distrito de un gabinete de Rarezas, Gabinete de Pinturas y una Biblioteca Pública - 1836 - En el Parlamento se pide un listado de los edificios de valor patrimonial y la prohibición de su venta - 1834- . Luís Mousinho de Albuquerque, ministro del Reino, encarga este inventario a la Academia de las Ciencias - 1836-. En 1840 él mismo como Inspector General de Obras Públicas clasifica los monumentos en tres clases. Sólo tres edificios se clasifican en ese tiempo como Monumentos Históricos - Batalha, Alcobaça y Mafra - Se crea en 1840 la Sociedad Conservadora de los Monumentos Nacionales y en 1849 la Sociedad Arqueológica Lusitana.

Este es el periodo setembrista - posterior a la revolución de septiembre de 1836 - una época de cierto interés por el patrimonio local a través de la prensa, las litografías y sus denuncias de vandalismo, pero son raras las actuaciones efectivas, aunque se suceden las medidas legislativas. Los proyectos de preservación por parte de los exilados retornados de Francia e Inglaterra empiezan a conocerse. Alexandre Herculano, en 1838, con el escrito "Monumentos pátrios" es el precursor de la salvaguarda de los monumentos nacionales. Es un documento duro y enérgico para denunciar el estado del patrimonio portugués, que utiliza expresiones como "instinto bárbaro, malevolência selvagem, a filosofia da brutalidade... agora derribam-se coruchéus, partem-se colunas, derrocam-se muralhas, quebram-se lousas de sepultura, e vão-se apagando todas as provas da história". Para Herculano, el vandalismo está en los mejores salones: "é culto, instruido, civil...podemos assegurar que dentro deste século não haverá em Portugal um monumento". Según él, los monumentos deben estar en su contexto: "não pedimos museus; porque estes não são, digamos assim senão necrópoles, em relação a arquitetura...os fragmentos de um edifício, tirados de seu lugar, sem destino, sem união, são mortos; são cinza e pó de cadáveres...as pedras só pedem repouso".

Para Herculano, el monumento es un escrito en piedra, un documento, un testimonio que nos desvela el pasado, tiene un interés cultural y constituye una forma de conocimiento. Se trata de la preservación de la propia historia, historia viva inscrita en el presente, de raíz identitaria que desvela los orígenes de una nación, un ideal colectivo capaz de unir a ricos y pobres. El objeto arqueológico surge como marca de una identidad. Se trata de fundar en un pasado remoto la unidad étnico-cultural

se arreglan algo las cosas, pero los frailes fueron las mayores víctimas del proceso en un difícil tiempo de transición, conflictos, ganancias, inestabilidad y crisis. 
del pueblo portugués, un proyecto nacionalista. Sin embargo, al ser el monumento un medio de prueba del discurso historiográfico, una fuente de legitimación, ello implica que tenga que mantenerse en su estado original; las alteraciones posteriores son falsificaciones, su destrucción constituye una forma de silenciar las pruebas de la historia (Prata, 2010). Aquí aparece, pues, la noción de autenticidad, de veracidad y de pureza inicial, que la restauración debe devolver al monumento retirándole los "vandalismos" que le fueran adosados, aunque esos "vandalismos" llevaran ya varios siglos. Cabe destacar que las ideas y la defensa de Herculano tienen su origen y concreción en su experiencia en el exilio, al igual que sucediera con Almeida Garret en relación al valor patrimonial de los conjuntos urbanos (Maia, 2005-6).

La época de 1868 y 1870 , en que se produce la restauración del templo, se encuadra dentro de la Regeneração, un planteamiento de desarrollo del país, pero sin democratizar las instituciones. Sin embargo, es un tiempo de crecimiento de una masa urbana politizada y militante, una fuerza política y social. En 1865 hay una terrible crisis financiera, con déficit, subida de precios, desempleo y aumento de suicidios. En el Alentejo la mendicidad se confundía con el bandidaje. A partir de 1867 un movimiento de protesta arrasó el país. Hubo una reforma administrativa y un impuesto al consumo. Justo en 1868 hay revueltas en el norte y un golpe militar en 1870 - la "saldanhada" - . Desde 1865 se produce la "questão coimbrã" o la "querela do bom senso e bom gosto", una generación que planteaba una nueva era en que los intelectuales serían la consciencia crítica del país y la ciencia serviría para regenerar la organización social. Un grupo de estudiantes de Coimbra planteaba restablecer el contacto de Portugal con la Europa "civilizada" y con la modernidad. Para ello se organizan las célebres "Conferências Democráticas do Casino" en 1871; se trataba, en palabras de Eça de Queirós, de hacer la revolución en su forma científica, en la región de las ideas y los datos de la ciencia frente al catolicismo, causa de la decadencia de Portugal y España ${ }^{26}$. Eça perteneció a la llamada generación de 1870, un grupo de jóvenes intelectuales liberales, muy influenciados por los pensadores franceses y la ideología masónica, racionalistas, positivistas y antimonárquicos.

En cuanto al patrimonio, en 1852 su gestión pasa a manos del Ministerio de Obras Públicas, Comercio e Industria, liderado por Fontes Pereira de Melo. En esta época se utiliza la designación de monumento histórico - 1852- y, posteriormente, de monumento nacional — 1869-, separando la intervención por una parte y la gestión y tutela por otra, que ostenta el Bibliotecario Mayor. En estos años parece haber una mayor sensibilidad hacia el monumento; por ejemplo, el rey Fernando II restaura como mecenas algunos edificios y recoge piezas procedentes de conventos, si bien son iniciativas exclusivas de las clases altas y los medios intelectuales. En otras ocasiones, se intenta preservar algunos edificios cediéndolos a diversas entidades - el convento de San Francisco y la Galería de las Damas del palacio de D. Manuel se dona al ayuntamiento de Évora—. Simões, treinta años después, se une a la crítica

${ }^{26}$ Estas ideas anticlericales, que se harán más virulentas en los siguientes años con la firma del Concordato y el tema de las Hermanas de la Caridad, son propuestas en las Confêrencias por Antero de Quental y Adolfo Coelho, tal como indica Bonifacio (2002: 88-89), a quien sigo en estas líneas. 
de Herculano en su Relatorio de 1869 denunciando el pésimo estado del patrimonio portugués, pero ya se refiere al pasado: "É tão natural sentimento dos povos cultos a veneração dos monumentos da antiguidade, que ninguém acreditaria, se o não visse bem patente o desprezo com que em Portugal tem sido tratados... comum furor de destruir, adulterar ou emplastar as relíquias da arquitetura...".

En 1870 y 1875 hay un esfuerzo serio, al nombrar comisiones para el análisis de la situación y un Servicio de Monumentos Históricos y de Arqueología que son poco operativos. En 1880 la Real Asociación de los Arquitectos Civiles y Arqueólogos portugueses hace un inventario y una clasificación del patrimonio construido, impulsado por Possidonio da Silva que, ya en 1858, había iniciado el primer levantamiento sistemático creando una red de corresponsales. En 1880 se publica el Relatório e Mapas acerca dos edifícios que devem ser classificados monumentos nacionais con seis clases, que se concretará en 1890 en una comisión de Monumentos Nacionales (Maia, 2005-6). Esas seis categorías incluyen monumentos prehistóricos, anteriores a la monarquía, de arte militar, de conmemoración, monumentos para el estudio de las artes y en la primera categoría "Monumentos históricos e artísticos e os edifícios que somente se recomendam pela grandeza da sua construção, pela sua magnificência, ou por encerrarem primores de arte", donde se incluye, junto a Batalha, Alcobaça y Jerónimos, al templo romano de Évora (Prata, 2010:16).

Bajo la influencia del movimiento regenerador, Évora se moderniza durante la segunda mitad del XIX. Desde entonces la ciudad, que estaba cerrada, sin espacios públicos ajardinados, se abre al exterior, con la preocupación de crear una mejor accesibilidad, por lo que las antiguas puertas de la ciudad desaparecen - excepto la puerta de Aviz-. En 1863, en presencia del Marquês de Sá da Bandeira, se inaugura el ferrocarril ${ }^{27}$. Para unir la estación y el centro aparece la Avenida Barahona, se puebla de árboles el Rossio y la ciudad crece fuera de las murallas. El ferrocarril tuvo sus opositores, ya que se consideraba que perdía autonomía la ciudad en relación a Lisboa, encarecía el precio de las mercancías y absorbía los productos alimenticios de la zona (CME, 2000) ${ }^{28}$.

Hasta finales del XIX, Évora mantendrá su estructura medieval con calles estrechas, pocas plazas y largos. No hay construcción en los terrenos de los antiguos conventos y en los fosos y la parte exterior de las murallas y muy poca vegetación en los espacios públicos. La ciudad tiene una arquitectura muy rural, sin agua, empedramiento, sumideros... Los jardines privados y patios conventuales se esconden por altos muros. Hay iluminación pública desde 1825 con aceite, petróleo en 1867 y, más tarde, a gas. Sin embargo, en la segunda mitad del siglo se aprecian ciertos cambios en la ciudad. En 1863 se empiedra la Praça do Giraldo, el centro cívico de

${ }^{27}$ Según Fonseca (1966:165), entre 1850 y 1910, el Alentejo se integra en la Región Económica del Sur, polarizada por Lisboa, que se acelera por la red ferroviaria y una cultura de cereal pero también por la industria y la diversificación de su oferta, hasta 1880 muy dinámica.

${ }^{28}$ Sobre el contexto evorense, me baso fundamentalmente en Riscos de um Século (CME, 2000), una excelente panorámica de finales del XIX y del siglo XX. Véase especialmente los textos del arquitecto Pinto Barbosa. También he consultado Fonseca (1996), Bernardo (2001) y el número 26 de Monumentos. 
la ciudad. En ese mismo año, frente al alzado norte del templo, se crea una plaza, el primer jardín publico de la ciudad, que toma el nombre de Passeio de Diana al concluirse las obras en 1863. En 1876 se construye la carretera de circunvalación. Se hacen cambios en el Palacio de D. Manuel en 1881 y en ese mismo año se inicia la construcción del Teatro Garcia de Resende. Cinatti construye el Palacio Barahona. La forma medieval comienza a ser modificada con más y mejores espacios públicos y nuevas prácticas de sociabilidad. Uno de ellos es el Passeio Público, símbolo de civilidad asociado al naturalismo y a los placeres bucólicos de los burgueses con sus románticas ruinas fingidas. Los conciertos al aire libre y el teatro que se comienza a construir son parte de esas nuevas formas. La sociabilidad eborense cambia profundamente entre 1867 y el final de siglo: una vida de lareira y de iglesia, centros de la vida social, dan paso a una activa sociabilidad a través de sociedades recreativas (Bernardo, 2001).

En definitiva, entre 1836 y 1871, un largo y atribulado proceso, llevado a cabo por hombres de cultura en la tradición intelectual y artística de la ciudad, permitió valorizar el templo en una época de desastre para el patrimonio cultural portugués (Dias, 2007-2008). Vamos a ver con algo más de detalle quienes son esos hombres cultos, los principales protagonistas que impulsan la restauración del templo.

Cunha Rivara (1809-1879) nació en Arraiolos, estudió en Évora y se licenció en Medicina en Coimbra. Fue profesor de filosofía en el Liceo y, entre 1838 y 1853, desempeñó gratuitamente el cargo de bibliotecario en la Biblioteca Pública de Évora ${ }^{29}$, una biblioteca que encontró en un completo abandono. Rivara donó casi doscientos libros antiguos, recoge miles de impresos y manuscritos de los conventos, extinguidos en 1834, produce un Catalogo dos Manuscritos da Biblioteca Pública Evorense de cuatro volúmenes y realiza la lectura y resumen de casi 10.000 documentos de la Cámara Municipal desde 1167 a 1838 (A Cidade de Évora, 43-44 hasta 69-70). Rivara realiza excavaciones en 1845 en el templo de Diana agotando una subscripción voluntaria e incluso aportando sus propios recursos "de que eu na minha pobreza pude dispôr..." (Branco, 2007: 119) ${ }^{30}$. Diputado liberal, tras pasar unos años en Goa, vuelve a Évora en 1877 poco antes de morir.

Su sucesor, Filipe Simões - 1835-1884 - nace en Coimbra, donde estudió, como Rivara, filosofía y medicina e, igual que él, fue profesor del liceo en 1863 y Bibliotecario de la Biblioteca Pública. Escribió el Relatorio de 1869, ya mencionado. Sus años en Évora son los de la Questão Coimbrã y el folleto Bom Senso e Bom Gosto; periodo de gobierno de Fusión, en que se elige el primer republicano en la Cámara de Diputados; de abolición de la pena de muerte; en que se crea el Código

${ }^{29}$ Sobre la vida de Rivara, escribió un Elogio el propio Simões, tal como recoge Branco (2007), de quien tomo estas semblanzas de Rivara y Simões.

${ }^{30}$ Rivara, sin embargo, no debía ser tan pobre, puesto que se le considera "grande propietario" en la Cronología de la Biblioteca de Évora. Fonseca (1996) le incluye entre los mayores contribuyentes en 1852 con casas de residencia, aunque se marchó a Arraiolos. Lemos, su compañero en las excavaciones, también "grande propietario", y Rector del Liceo, le sustituirá como Bibliotecario Interino en 1855. También Lemos aparece como contribuyente en 1858-60 con varias residencias y casa nobre. (http://www.evora.net/bpe/cronologia.htm). 
Civil portugués; de impuesto de consumo; cuando se suprimen las primogenituras; se crean los primeros bancos; llega el ferrocarril; y se produce un historicismo y nacionalismo militante y el inicio de las exposiciones universales. Fue catedrático en Coimbra. Publicó una obra pionera dedicada a la arquitectura romana - Relíquias da arquitetura romano-bizantina em Portugal, 1870- Y muere trágicamente a los 48 años.

Ambos autores son los primeros bibliotecarios civiles, liberales, de fuera de la ciudad y a la vez enamorados de ella. En los dos casos, a pesar de su formación y profesión, tienen un interés poco común por la arqueología y el arte romano que practican con pasión. Pero hay algo que los distingue en relación a la restauración del templo: mientras Rivara propone mantener una parte de las paredes de la Edad Media - al igual que Feliciano de Castilho, otro de los consultados, que propone dejarlo tal como estaba-, Simões y Herculano se decantan por la desnudez del templo. Herculano indicó que "não devia ficar nada que não fosse primitivo e romano, porque tudo o mais não tinha merecimento algum histórico ou artístico e só poderia servir de arrastar um dia, na sua ruína, o que era precioso" (cit. en Rodrigues y Matos, 2007: 138). Esta diversidad de opiniones supone una diferencia de lo que implica el monumento: los primeros destacan su valor artístico e indican que las transformaciones del monumento son parte de su historia; el templo es una estructura estratificada donde se pueden identificar diferentes momentos de la historia de la comunidad. Los segundos consideran los cambios profanaciones e enmascaramientos del auténtico documento histórico; puesto que el concepto de historia está asociado, como vimos, a la idea de autenticidad y pureza, cualquier cambio es una falsificación de la historia.

Tenemos, pues, el triunfo de la "Inmaculada Concepción del Monumento" que se aplicará al templo de Diana, así como una decidida apuesta por el pasado romano de la ciudad o la construcción de una genealogía con pedigree, donde incluso el romano Sertorio es más relevante que Viriato, el héroe lusitano ${ }^{31}$. El templo se convertirá en el exlibris de la ciudad y un monumento imprescindible de su historia. A partir de la restauración del templo, los eborenses se apercibieron visualmente del origen romano de la ciudad y el monumento, que la corona en su zona más elevada, reestructuró la ciudad y sirvió para reconstruir la imagen posterior. Los afanes de sus defensores motivaron a otros posteriores - Gabriel Pereira, el Grupo Pro-Évora ${ }^{32}$, Túlio Espanca...- creando un pionero ambiente de protección y defensa de la ciudad. En su artículo "Restaurar para renovar na Évora do século XIX" Rodrigues y Matos (2007: 139) indican: "Mais do que reconstituido no estilo original, o templo foi recriado enquanto ruína, que na sua semi-existência arquitetónica era o símbolo perfeito de um passado distante e irreversivel".

¿Qué significado tiene la ruina? La ruina entronca en la poética y estética romántica. No olvidemos que el propio Cinatti pobló el Paseo Público de ruinas

${ }^{31}$ Véase un artículo de Leal (2001) sobre las tesis lusitanistas antropológicas y su relación con la arqueología.

${ }^{32}$ Sobre el tema, ver David (1944) y David y Rodrigues (2001). También hay unas páginas sobre ello en Cátedra (2010). 
fingidas, controladas, con un carácter escenográfico, una especie de estética de la degradación amansada. El siglo XIX portugués se caracteriza por este tipo de ruinas góticas y manuelinas, sacadas de su contexto. Garrett valoriza las ruinas como lugar poético de comunión con la naturaleza y también como signos de movimientos revolucionarios, portadores de libertad (Rosas, 1995).

Zulaika ha planteado una "teoría de las ruinas" (2006: 188-191) en relación a Bilbao, que paso a resumir para terminar y que puede ser también aplicada al templo de Diana. Según Zulaika, las ruinas condensan e identifican el significado de edificios, teorías e historicidades y proporcionan la identidad residual para culturas con ansias de conversión. Sirven como emblemas definitivos sobre el paso del tiempo, desvelan las pretensiones míticas de eternidad de cualquier edificio y reflejan la cualidad efímera de las mercancías expuestas, la verdad definitiva. No hay antídoto mejor para las ambiciosas falacias construidas por el mito, los sueños, los deseos y la fantasmagoría urbana que contemplar sus ruinosos resultados, proporcionan el movimiento de historias y sujetos mediante la visualización de la transitoriedad de cualquier constructo. La ruina es el antídoto de las pretensiones de eternidad de cualquier edificio, pertenece a un pasado muerto que permanece sólo como significado; cuanto mayor sea la ruina, más incisivo será su significado. Pero la ruina es la precondición para el cambio económico y social, anuncia las nuevas fases de regeneración urbana, un proceso continuo de decadencia y renovación. Autoriza y exige nuevos comienzos, legitima la mitología de un comienzo y un progreso futuro. Así, las ruinas llenan el marco de la vida urbana y la experiencia social. Las ruinas hacen posible que las sociedades y las gentes visualicen la vulnerabilidad de sus proyectos. Las ruinas pueden llevar a la nostalgia, la melancolía, la desesperación, a la búsqueda de un refugio alegórico en "otro mundo" idealizado, pero también pueden transformarse en esperanza y sueño y construir un nuevo mundo. $\mathrm{O}$ al menos una nueva ciudad.

\section{Referencias bibliográficas}

ABREU, Susana Matos

s. a. "De Roma a Évora, com André de Resende: Cidade e Patrimonio na Historia da Antiguedade da cidade de Évora”. ms. http://www.apha.pt/boletim/boletim2/pdf/ Susana_Matos_Abreu.pdf.

ANÓNIMO

1836 "Ruinas de Portugal", en De Historia, Bellas Letras y Artes. El Instructor: ó Repertorio, vol. 3: 169-172. books.google.es/books?id=cfkaAAAAYAAJ...

BARATA, António Francisco

1872 Instituto Vasco de Gama. Tomo I: 200 aprox.

1878 "Restauração do templo romano en Évora", en Miscelanea historico-romantica. Barcellos, Typographia da Aurora do Cavado, 185-203. 
BERNARDO, Maria Ana

2001 Sociabilidade e distinção em Évora no século XIX. O Círculo Evorense. Lisboa: Edições Cosmos.

BONIFACIO, M. Fátima

2002 O século XIX português. Lisboa: Imprensa de Ciencias Sociais.

BRANCO, Manuel J. C.

2007 "A defesa do patrimonio construído em Évora. Cunha Rivara, Filipe Simões, Gabriel Pereira e Túlio Espanca”, en Dossié: Centro Histórico de Évora. Monumentos, 26: 118-123.

CÁTEDRA María

2010 "Imaginar y crear una ciudad: el Grupo Pro-Évora", en Camila del Mármol, Joan Frigolé y Susana Narotzky (eds.), Los lindes del patrimonio. Consumo y valores del pasado. Barcelona: Icaria, ICA, 61-84.

CME. Câmara Municipal de ÉvorA

2000 Riscos de um Século. Catálogo de Exposição. Évora: Câmara Municipal de Évora.

COSTA, Antonio Carvalho da

1708 Corografia Portugueza. Lisboa.

DAVID, Celestino

1944 “O Grupo Pro-Évora. Páginas comemorativas do 25º aniversário 1919-1944 (Sua origem e fundação, fases por que tem passado, espírito e obras)". A Cidade de Évora, 7-8: 3-41, 103-253. Évora: Câmara Municipal de Évora.

DAVID, Celestino Froes; RODRIGUES, Marcial

2001 Pela Biblioteca Pública de Évora. Defesa de uma Instituição Cultural. Évora, Grupo Pro-Évora Edições.

ESTAÇO, Gabriel

1625 Varias Antiguedades de Portugal.

FARIA

1785 En Farinha, Bento Joze de Souza. Colleçam das antiguidades de Évora. Lisboa: Na Officina de Filippe da Silva e Azev.

FIALHO, Manuel

1942-1944 [ms. 1718] Evora ilustrada en A Cidade de Évora. Año1, no 1. Fascículos 1-6.

FONSECA, Francisco de

1728 Évora gloriosa. Epílogo dos quatro Tomos de Évora Ilustrada que compoz o R.P.M. da Companhia de Jesu. Roma: Na officina Komarckiana.

FONSECA, Helder Adegar

1996 O Alentejo no século XIX. Economia e attitudes económicas. Lisboa: Imprensa Nacional Casa da Moeda. 
FRANCO, Antonio

1945 [ms. 1728] Évora Ilustrada extraida da obra do mismo nome do P. Manuel Fialho. Évora, Edições Nazareth.

HAUSCHILD, Theodor

1991 "El templo romano de Évora", en Templos romanos de Hispania. Cuadernos de arquitectura romana, I: 107-117.

HERCULANO, Alexandre

1983 [1838-9] "Monumentos patrios", en Jorge Custódio y J. M. Garcia (orgs.), Opúsculos I. Lisboa: Presença.

LEAL, João

2001 "Las tesis lusitanistas. Arqueología y Antropología en Portugal". Complutum, 12: 297-309.

MAIA, Maria Helena

2005-2006 "De bienes de la nación a monumentos nacionales. Romanticismo y patrimonio arquitectónico en Portugal”. Espacio, Tiempo y Forma, serie VII, $\mathrm{H}^{\mathrm{a}}$ del Arte, t. 18-19.

PRATA, Jorge Manuel de Matos Pina Martins

2010 A emergência da noção de património. Pós-Graduação em Direito do Património. Instituto de Ciências Jurídico-Políticas. Faculdade de Direito da Universidade de Lisboa.

RESENDE, André de

1783 [1576] Historia da Antiguidade da Cidade de Evora. $3^{\mathrm{a}}$ edición copiada de la segunda de 1576 y enmendada por el autor. Lisboa: Of. S.T. Ferreira.

RODRIGUES, Paulo Simões; MATOS, Ana Cardoso de

2007 "Restaurar para renovar na Évora do século XIX”, en Dossié: Centro Histórico de Évora. Monumentos, 26: 136-9.

ROSAS, Lúcia Maria Cardoso

1995 Monumentos Pátrios. A arquitectura religiosa medieval-património e restauro (18351928). Porto: Dissertação de doutoramento em História de Arte apresentada à Faculdade de Letras da Universidade do Porto.

SARAIVA, José Hermano

1989 Historia de Portugal. Madrid: Alianza.

SILVA, António Carlos

1997 "Évora romana. Do mito à história", en VV.AA, Évora, História e Imaginário. Évora: Ataegina.

SILVA, António Martins da

1994 “A desamortização”, en J. Mattoso (ed.), História de Portugal, 5:293-305. Lisboa: Estampa. 
SILVEIRA Luís Espinha

1991 "Venda de bens nacionais, estructura da propiedade e estructura social na região de Évora na primera mitade do século XIX”. Análise Social, XXVI, 112-3:585-612.

SIMÕES, Augusto Filippe

1869 Relatorio ácerca da renovação do museu Cenaculo, dirigido ao ex.m ${ }^{\circ}$ sr. Vizconde da Esperança, presidente da camara municipal de Evora. Évora: Cãmara Municipal.

1888 “O templo romano de Evora", en Escriptos Diversos. Coimbra: Imprensa da Universidade.

VASCONCELLOS, Diogo Mendes

1785 [1593] "Libro V do Municipio Eborense”, en Farinha, Bento Joze de Souza (eds.), Colleçam das antiguidades de Évora. Lisboa: Na Officina de Filippe da Silva e Azev.

ZULAIKA, Joseba

2006 "Las ruinas de la teoría y la teoría de las ruinas". Revista de Antropología Social, 15:173-192. 